\title{
Errata
}

A Correction to: "Operator Convex Functions of Several Variables" (Vol. 33, No. 3, 1997, pp. 443-463)

By

\section{Frank HANSEN*}

page $458, \uparrow 3$

text as printed

$$
\Phi^{a}\left(m_{1}, \cdots, m_{k}\right)=\left(\begin{array}{c}
\Phi_{1}^{a}\left(m_{1}, \cdots, m_{k}\right) \\
\vdots \\
\Phi_{k}^{a}\left(m_{1}, \cdots, m_{k}\right)
\end{array} \quad m_{i}=1, \cdots, n_{i} \text { for } i=1, \cdots, k\right)
$$

correction

$$
\Phi^{a}\left(m_{1}, \cdots, m_{k}\right)=\left(\begin{array}{c}
\Phi_{1}^{a}\left(m_{1}, \cdots, m_{k}\right) \\
\vdots \\
\Phi_{k}^{a}\left(m_{1}, \cdots, m_{k}\right)
\end{array}\right) \quad m_{i}=1, \cdots, n_{i} \text { for } i=1, \cdots, k
$$

page 463, References of [10] and [11].

text as printed

[10] - Jensen's operator inequality for functions of two variables, Proc. Amer. Math. Soc., 1996.

[11] Hansen, F. and Pedersen, G. K., Jensen's inequality for operators and Löwner's theorem, Proc. Amer. Math. Soc., 125 (1997), 2093-2102.

\section{corrections}

[10] Jensen's operator inequality for functions of two variables, Proc. Amer. Math. Soc., 125 (1997), 2093-2102.

[11] Hansen, F. and Pedersen, G. K., Jensen's inequality for operators and Löwner's theorem, Math. Ann., 258 (1982), 229-241.

* Institute of Economics, University of Copenhagen, Studiestraede 6, DK-1455 Copenhagen K, Denmark. 
